\title{
Article
}

\section{Escherichia coli 0157:H7 Requires Colonizing Partner to Adhere and Persist in a Capillary Flow Cell}

Benjamin J. Klayman, Paul A. Volden, Philip S. Stewart, and Anne K. Camper

Environ. Sci. Technol., 2009, 43 (6), 2105-2111• DOI: 10.1021/es802218q • Publication Date (Web): 18 February 2009

Downloaded from http://pubs.acs.org on March 16, 2009

\section{More About This Article}

Additional resources and features associated with this article are available within the HTML version:

- Supporting Information

- $\quad$ Access to high resolution figures

- $\quad$ Links to articles and content related to this article

- $\quad$ Copyright permission to reproduce figures and/or text from this article

\section{View the Full Text HTML}


Escherichia coli 0157:H7 Requires Colonizing Partner to Adhere and Persist in a Capillary Flow Cell

\author{
B ENJAMIN J. KLAYMAN, * \\ PAULA. VOLDEN, PHILIP S. STEWART, \\ AND ANNE K. CAMPER \\ Center for Biofilm Engineering, Montana State University, \\ 366 EPS Building, Bozeman, Montana 59717
}

Received October 30, 2008. Revised manuscript received January 23, 2009. Accepted January 26, 2009.

The ability of a strain of waterborne Escherichia coli 0157: $\mathrm{H} 7$ to colonize a glass flow cell and develop microcolonies when grown alone and with Pseudomonas aeruginosa PA01 was examined. When introduced alone, planktonic $E$. coli were unable to attach to the glass surface. When introduced simultaneously with $P$. aeruginosa (co-inoculation), the two species coadhered to the surface. When $E$. coli were introduced into a flow cell precolonized with a $P$. aeruginosa biofilm (precolonized), 10 -fold more cells were retained than in the coinoculated case. Both species were monitored nondestructively by time-lapse confocal microscopy, direct microscopy of the filtered effluent, and effluent plate counts. While more $E$. coli initially adhered in the precolonized system, E. colimicrocolony formation occurred only in the co-inoculated system, where E. coli comprised $1 \%$ of the total surface-associated biovolume but greater than $50 \%$ of the biovolume near the edges of the flow cell. The hydrodynamics in the flow cell were evaluated using the finite volume analysis program CFX, revealing that shear stress was likely important in both initial attachment and steadystate colonization patterns. This research elucidates key factors which promote retention and subsequent biofilm development of E. coli 0157: $\mathrm{H} 7$.

\section{Introduction}

Bacteria exist in nature primarily in communities known as biofilms. These biofilms are usually characterized by differentiated structures, exhibit a different phenotype than their planktonic counterparts, and in nature most often consist of multispecies consortia $(1,2)$. An important process in shaping the formation and structure of some multispecies biofilms is the ability of certain species to coaggregate. In this process, planktonic cells adhere to genetically distinct cells in a biofilm or to other planktonic cells (3), thereby increasing biofilm formation. This process is growth-phasedependent and is turned on and off by cells, suggestive that it may also play a role in dispersal and dissemination (4). Due to these and other complexities of the biofilm mode of growth, multiple species can coexist despite one organism having a much higher growth rate than another $(5-7)$.

In many cases, bacteria have been shown to gain a fitness advantage when residing in a mixed-species versus single-

\footnotetext{
* Corresponding author tel: (913) 458-2370; e-mail: klaymanbj@ bv.com. Current address: Black \& Veatch, 8400 Ward Parkway, Kansas City, MO 64114.
}

species biofilm. Bacteria living in a two-species community were demonstrated to undergo mutations which improved productivity and stability compared to the parent community (8). A Lactobacillus strain has been found to persist at up to 20 times higher cell numbers in a mixed-species biofilm than in monoculture (9). In addition to greater biomass in mixedspecies versus single-species biofilms, increased resistance to antimicrobial treatment has been noted (3). In extreme cases, bacteria which were unable to adhere or form biofilms alone were able to do so in coculture $(10,11)$.

Escherichia coli $\mathrm{O} 157: \mathrm{H} 7$ is a bacterial pathogen in both food and water, and its abilities to form biofilms under static conditions (12-16) as well as coaggregate (17) have been reported. Biofilms in drinking water distribution systems (18-20) and porous media systems such as biofilters and model groundwater aquifers $(21-23)$ have been shown to harbor organisms such as E. coli. It is therefore desirable to examine pathogen survival under flowing conditions as well as static ones. While previous studies have monitored pathogen persistence at the reactor-scale level, a finer-scale analysis in a flowing system could be used to quantify localized population heterogeneities, that is, where pathogen integration occurs.

In this study, the authors monitored biofilm formation using confocal microscopy and location-specific pixel counting to quantitatively describe spatial and temporal patterns of colonization of a dual-species biofilm with fluorescentprotein-labeled E. coli $\mathrm{O} 157: \mathrm{H} 7$ and $P$. aeruginosa $\mathrm{PAO} 1$ in a flowing system. This information can be used to better understand pathogen persistence in the environment and will be integrated into computer models of pathogen persistence currently being developed.

\section{Materials and Methods}

Bacterial Strains, Plasmids, and Media. The E. coli O157:H7 was a waterborne isolate obtained from Dr. Barry Pyle, Department of Microbiology, Montana State University. To make the E. coli strain electrocompetent, $1 \mathrm{~mL}$ of an overnight culture grown in Luria Broth (LB) was added to $100 \mathrm{~mL}$ of fresh $\mathrm{LB}$, shaken for $2 \mathrm{~h}$, and then placed on ice. The E. coli cells were washed three times in cold, sterile $10 \%$ glycerol and resuspended to a final volume of $500 \mu \mathrm{L}$. A constitutively expressing DsRed-express plasmid (Clontech) was then inserted by electroporation (Eppendorf Electroporator 2510; $1500 \mathrm{~V}$ ), and transformants were selected by plating on LB agar and $250 \mathrm{mg} / \mathrm{L}$ of carbenicillin (Fisher Bioreagents). Pseudomonas aeruginosa $\mathrm{PAO} 1$ contained a constitutively expressing green-fluorescent protein (GFP) plasmid described previously (24) and was obtained from Dr. Mike Franklin, Department of Microbiology, Montana State University. A total of $250 \mathrm{mg} / \mathrm{L}$ of carbenicillin was added to all media described herein unless otherwise noted.

Single- and Dual-Species Planktonic Growth Curves. Cells were streaked for isolation from a frozen glycerol stock on Tryptic Soy Agar (TSA, BD Difco). Cells were then stepped down into successively lower nutrient concentrations as follows: A single colony was placed into $4 \mathrm{~mL}$ of $10 \%$ Tryptic Soy Broth (TSB, EMD) and shaken for $24 \mathrm{~h}$ at $180 \mathrm{rpm}$ at 25 ${ }^{\circ} \mathrm{C}$. A total of $40 \mu \mathrm{L}$ of this culture was spiked into $4 \mathrm{~mL}$ of $1 \%$ TSB and shaken as before, which was then used as the inoculum for the growth curve. Experiments were conducted with and without antibiotic. For dual-species experiments, the volumes of the 24-h inoculum cultures were adjusted to contain a 50:50 ratio of the two species. At each sample time, $500 \mu \mathrm{L}$ was vortexed, serially diluted (1/4× Ringer, Oxoid), and plated using the drop plate method (25). The two species 
could be differentiated on an agar plate by colony color. The $\mu_{\max }$ values are reported as mean \pm standard error from three replicate experiments and were calculated from the slope of the least-squares fitted line of the $\ln (\mathrm{cfu} / \mathrm{mL})$ versus time plot during the exponential phase (hours 3-9 and 3-13 for E. coli and P. aeruginosa, respectively).

Biofilm Reactor Design and Operation. Biofilms were grown in $0.9 \times 0.9 \times 150 \mathrm{~mm}$ square cross-section glass capillary tubes (Friedrich and Dimmock, NJ). Four parallel flow cells (baked at $300{ }^{\circ} \mathrm{C}, 5 \mathrm{~h}$ ) were independently fed by silicone tubing with one input line for sterile $1 \%$ TSB media (no antibiotic during biofilm growth), and a separate input line for culture inoculation. Downstream was a port for collecting effluent samples. The assembly was autoclaved 20 min prior to inoculation. The design flow rate was $24 \mathrm{~mL} / \mathrm{h}$, which corresponds to a Reynolds number of 10 (laminar flow). The reactors were left on the microscope stage (25 \pm $2{ }^{\circ} \mathrm{C}$ ) for the duration of the experiment.

Inoculation Procedure. Planktonic E. coliwere introduced either alone into a clean glass flow cell (clean glass), simultaneously with $P$. aeruginosa into a clean glass flow cell (co-inoculated), or alone into a flow cell precolonized with a mature (72-h) P. aeruginosa biofilm (precolonized). Overnight cultures were spiked into fresh $10 \%$ TSB and shaken for $5 \mathrm{~h}$ at $30^{\circ} \mathrm{C}$. A total of $10 \mathrm{~mL}$ of the E. coli culture $(2.7$ $\times 10^{8}$ cells $/ \mathrm{mL}$ ) was placed in a $100 \mathrm{~mL}$ bottle and used as the inoculum in all experiments. In the co-inoculation case, the volume of $P$. aeruginosa cells was adjusted to result in a final concentration of $2.7 \times 10^{6}$ cells $/ \mathrm{mL}$. This was to account for the greater attachment efficiency exhibited by $P$. aeruginosa and produced a uniform layer of surface colonization. Coaggregation of the inoculum was measured qualitatively by direct epifluorescence microscopy using a Nikon E800 scope equipped with FITC (GFP) and TRITC (DsRed) filters. In the precolonized case, $10 \mathrm{~mL}$ of the $P$. aeruginosa spike culture was inoculated in the same manner as E. coli. Sterile media flowed for $72 \mathrm{~h}$ at the design flow rate to allow for the development of a roughly steady-state biofilm. E. coli cells were then introduced in an identical manner to that described for the clean glass case. In all cases, the cells were introduced continuously at the design flow rate (24 $\mathrm{mL} / \mathrm{hr}$ ) for $15 \mathrm{~min}$. A schematic of the inoculation procedure is shown in the Supporting Information as Figure S1.

Confocal Microscopy and Image Analysis. All images were taken on a Leica SPS2 AOBS single-photon confocal microscope with a 488 laser set to $15 \%$ power for GFP excitation and a $561 \mathrm{~nm}$ laser at $75 \%$ power for DsRed excitation. Three-dimensional stacks were collected (without stoppage of flow) three times daily at three randomly preselected and marked fields of view per flow cell such that the same fields of view were monitored over the course of the experiment. Six independently fed flow cells from two separate experiments were evaluated for each inoculation case $(\times 3$ fields of view $=18$ data points). Images were collected using a $40 \times$ objective to quantify the attachment of single cells, and a $10 \times$ objective was used to show patterns of biofilm formation across the surface of the flow cell. The IMARIS software package (Bitplane AG, Zurich, Switzerland) was used to recreate confocal images into three-dimensional renderings.

Quantitative analysis was performed using Metamorph (Universal Imaging Corporation, Downingtown, PA). The number of attached cells per field of view was counted and scaled up to cells per square centimeter and is reported as mean \pm standard error. A user-defined script was written for calculating volumes occupied by each species. The threshold intensity value was set manually for each fluorescent label and then applied uniformly to all images. The pixels with an intensity value above the threshold in each plane were converted to area $\left(\mu \mathrm{m}^{2}\right)$ and summed over the set of $z$-stack planes. The user-defined script allowed for volume calculation at any location within a field of view. The P. aeruginosa migration velocity $(\mu \mathrm{m} / \mathrm{h})$ was calculated by measuring the distance that the leading edge moved from one image to the next, and dividing by the change in time between images.

Computational Fluid Dynamics. CFX (version 10.0, ANSYS Europe Ltd.) was used to evaluate the velocity and shear stress profiles in the clean square capillary. The flow cell geometry was created in ANSYS Workbench and imported into CFX. Input values for the model were the design flow rate $(8.3 \mathrm{~mm} / \mathrm{sec})$, zero velocity at wall surfaces (no-slip), and an outlet pressure of $1 \mathrm{~atm}$. A final mesh size of 901966 tetrahedral elements (167 803 nodes) was used for calculations. The strain rate $\left(\mathrm{s}^{-1}\right)$ generated by CFX is multiplied by the dynamic viscosity of water at $25^{\circ} \mathrm{C}\left(8.91 \times 10^{-4} \mathrm{~N} \cdot \mathrm{s} / \mathrm{m}^{2}\right)$ to obtain the shear stress $\left(\mathrm{N} / \mathrm{m}^{2}\right)$.

Effluent Analysis. Effluent samples were collected at each image acquisition time. A minimum of $500 \mu \mathrm{L}$ was collected, vortexed for $20 \mathrm{~s}$, serially diluted ( $1 / 4 \times$ Ringer), and plated on TSA. Another $500 \mu \mathrm{L}$ was collected simultaneously and vacuum-filtered (intact sample) on $0.2 \mu \mathrm{m}$ polycarbonate filters for direct epifluorescence microscopy. A total of 10 randomly selected fields were imaged for each filter with a $40 \times$ objective. The percent of $E$. coli coaggregated with $P$. aeruginosa was calculated by overlaying the two channels and counting by hand the total number of $E$. coli cells in direct contact with a $P$. aeruginosa cell, and dividing by the total number of $E$. coli cells per field of view.

Statistical Analysis. Statistical analysis was performed using MINITAB Release 14 (Minitab, Inc.). Point estimates are reported as the mean \pm standard error. $t$ tests determined whether two means were statistically significantly different. A linear regression model was performed on the log of the biovolume values to check for statistically significant increases in biovolume with time. Analysis of variance was performed on the log values of measured biovolume to estimate the variance between lines and between experiments.

\section{Results}

Batch Culture Experiments. Planktonic growth curves were conducted under the same nutrient conditions as the biofilm experiments. E. coli grew approximately $50 \%$ faster, with a $\mu_{\max }( \pm$ SEM, standard error of the mean) value of $0.64( \pm 0.01)$ $\mathrm{h}^{-1}$, compared to $0.40( \pm 0.03) \mathrm{h}^{-1}$ for $P$. aeruginosa. Identical $\mu_{\max }$ values were exhibited when grown in the presence or absence of antibiotic, or when grown together.

E. coli Attachment. E. coli was introduced under continuous flow conditions into a clean glass capillary flow cell for $15 \mathrm{~min}$. Confocal microscopy revealed that no cells irreversibly attached to the glass, even though some of the E. coli cells associated with the glass and twitched in a direction perpendicular to the flow, but these events lasted only seconds and were always followed by detachment.

Planktonic E. coli (DsRed) and P. aeruginosa (GFP) cells were simultaneously introduced (co-inoculation) into a clean glass capillary under the same flow conditions as in the clean glass case. Both E. coli and P. aeruginosa cells remained irreversibly associated with the glass. All observed E. coli cells were in direct physical contact with an attached $P$. aeruginosa cell. Microscopic examination of the inoculum revealed that coaggregation of the cells occurred prior to inoculation. The average $( \pm$ SEM) attached population of $E$. coli after the initial inoculation period was $2.6 \times 10^{3}( \pm 2.7$ $\times 10^{2}$ ) cells $/ \mathrm{cm}^{2}$.

Planktonic E. coli cells were also introduced into a flow cell precolonized with a 72-h $P$. aeruginosa biofilm. The $P$. aeruginosa biofilm was a flat slab approximately $50 \mu \mathrm{m}$ thick in the center of the flow path, with a mixture of individual microcolonies and voids near the edges. As detected by confocal microscopy, significantly more E. coli cells $(P=$ 

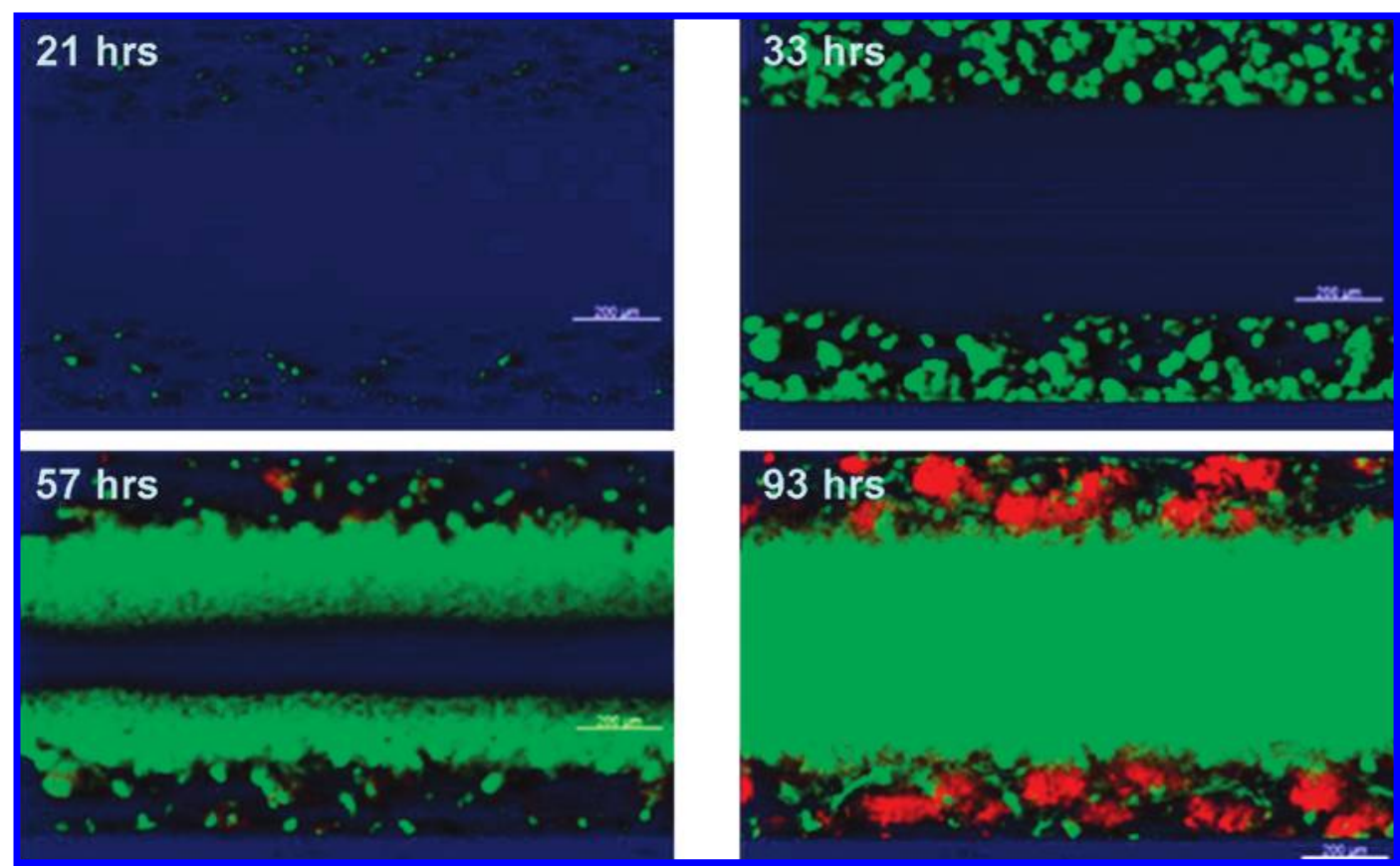

FIGURE 1. Time lapse confocal microscopy showing (top view) biofilm development from a $P$. aeruginosa (green) and $E$. coli (red) dual-species biofilm following co-inoculation into a clean flow cell. At a steady state $(93 \mathrm{~h}), \boldsymbol{P}$. aeruginosa preferentially colonizes the center of the flow path, and $E$. coli colonizes the outer 200 um edges (flow is from left to right).

$0.018)$ adhered in the precolonized flow cell $\left(1.6 \times 10^{4} \pm 7.7\right.$ $\times 10^{3}$ cells $/ \mathrm{cm}^{2}$ ) than in the co-inoculated one. The predominant location of trapped cells was between the $P$. aeruginosa biofilm and the glass substratum. Only a few cells were found on the surface of the biofilm, and a few others were located in channels within the biofilm (Figure S2, Supporting Information). No E. coli attachment was detected in previously uncolonized locations.

Biofilm Development. P. aeruginosa and E. coli dualspecies biofilm development was monitored at regularly scheduled intervals for $93 \mathrm{~h}$. No E. coli biofilm development occurred when introduced on clean glass, as no E. coli cells attached irreversibly. In 2 of the 18 fields of view for the precolonized case, some minor microcolony development was observed at the outer edges of the flow path. No development was seen in the other 16 cases. When averaging the 18 fields of view, accumulation was not significantly different from zero $(P=0.52)$.

Significant E. coli biofilm development was seen in the co-inoculated reactors $(P<0.001)$. Three-dimensional confocal images of biofilm development in a co-inoculated flow cell are shown in Figure 1. At early time points in the coinoculated reactor, the initial attachment for both species and early microcolony development occurred at the outer $200 \mu \mathrm{m}$ edge of the flow path. P. aeruginosa was the predominant species in the flow cell for the first $36 \mathrm{~h}$ of biofilm development.

After initial growth in the corners and beginning at hour 33, the Pseudomonas biofilm migrated perpendicular to the flow direction and built a dense wall of cells parallel to the flow direction, gradually expanding toward the center of the flow cell at a mean $( \pm$ SEM) velocity of $7.5( \pm 1.8) \mu \mathrm{m} / \mathrm{h}(57 \mathrm{~h})$. This migration vacated the edges of the flow cell, which was subsequently occupied by E. coli. E. coli developed into mature microcolonies along this outer $200 \mu \mathrm{m}$ edge of the flow cell and was never found in the center of the flow path. Pseudomonas, at the end of the 93-h experiment, existed in a flat-slab structure $500 \mu \mathrm{m}$ wide at the center of the flow path, along the entire length of the flow cell. This structure was very uniform, with little surface roughness. The entire movie of biofilm formation can be seen at http://www.

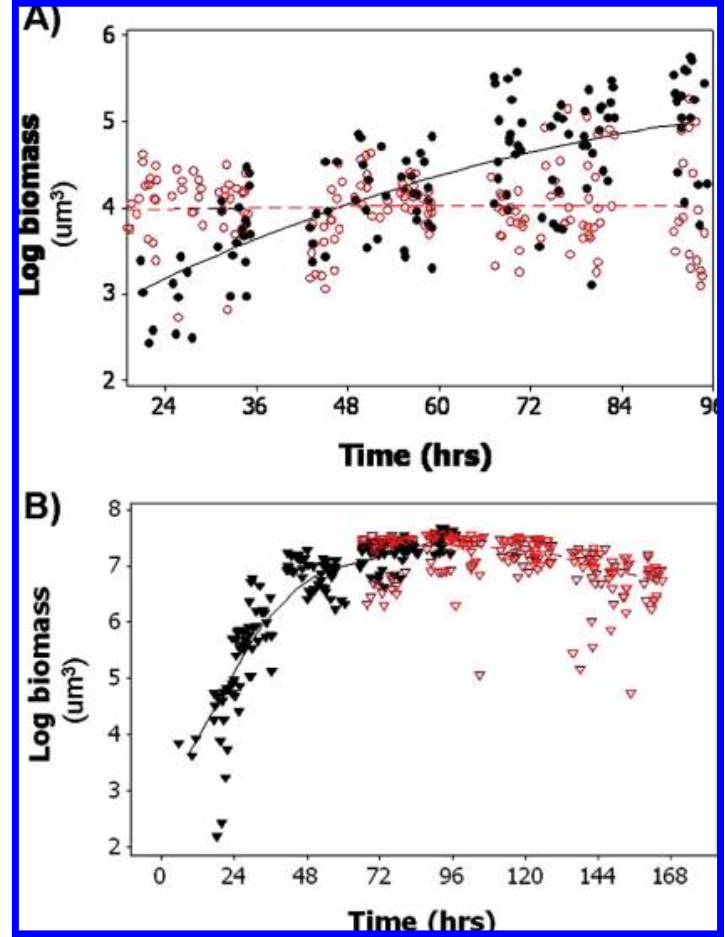

FIGURE 2. Log biomass for E. coli (A) and P. aeruginosa (B) versus time. Open symbols, precolonized; closed symbols, co-inoculated. Data points represent one of three fields of view for each of six independent flow cells (18 measurements per time point). Points were randomly jittered to avoid overlap.

biofilm.montana.edu/Res-Lib99-SW/Movies/Database/MD_ DisplayScript.asp.

A plot of the biovolume of each species versus time is shown in Figure 2. The P. aeruginosa plot shows exponential accumulation between 9 and $48 \mathrm{~h}$ that leveled off around 72 h. E. coli accumulation occurred at a much slower rate and continued increasing for $93 \mathrm{~h}$. 


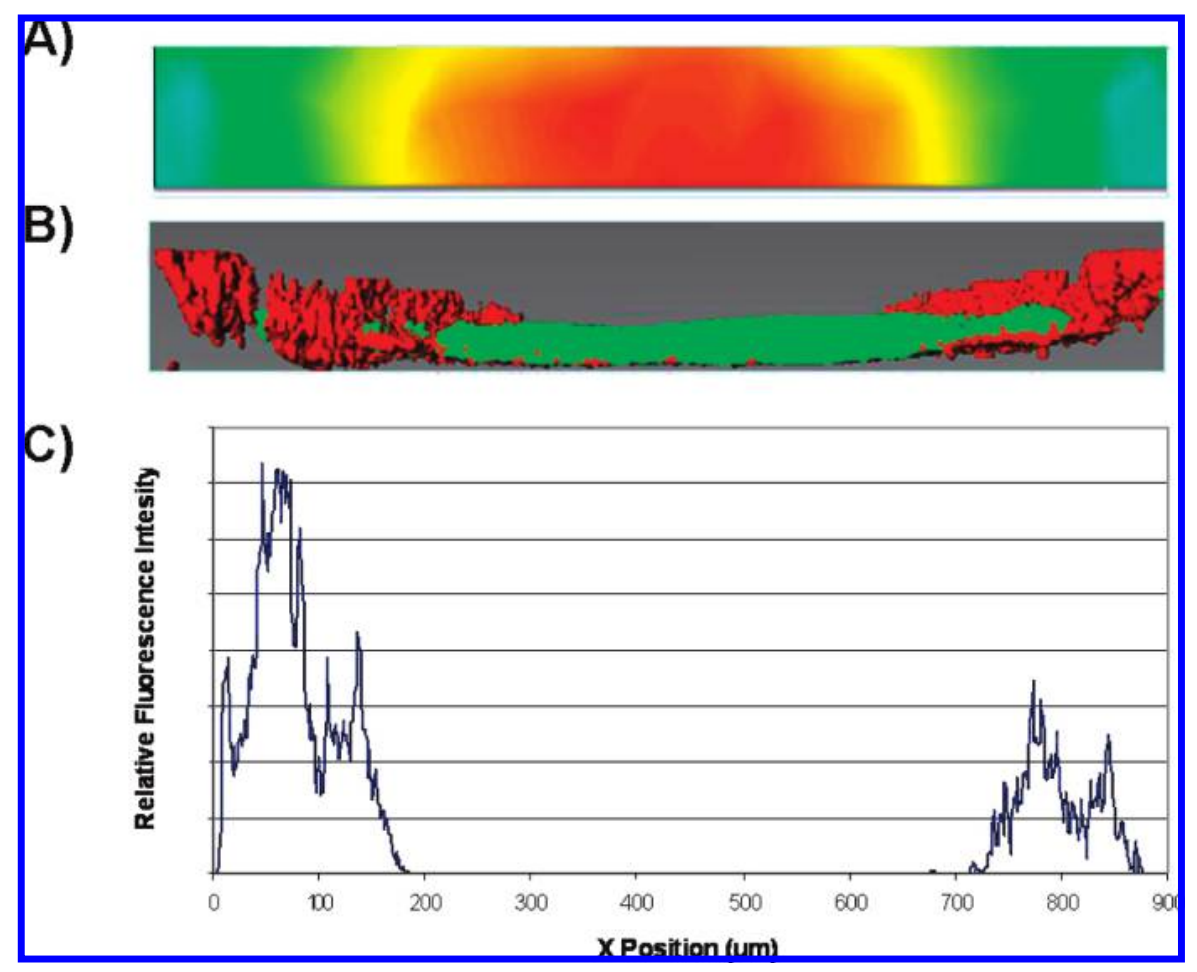

FIGURE 3. Strain rate profile generated in CFX (A) showed that the shear force is highest in the center of the flow path (red), and lowest in the corners (blue and green). (B) $E$. coli (red) colonized the low shear regions, while $P$. aeruginosa (green) colonized the higher shear regions in the center. The line scan feature in Metamorph (C) shows quantitatively that $E$. coli persisted only in the outer $200 \mu \mathrm{m}$ of the flow path.

The fraction of total biovolume occupied by each species across the entire surface and at the outer edges only was calculated at each time point and is shown in Figure S4, Supporting Information. E. coli accounted for only $1 \%$ of the total attached biovolume by $93 \mathrm{~h}$. When the biovolume is calculated separately for the outer $200 \mu$ m edges of the flow path, E. coli accounts for over $50 \%$ of the total biovolume.

Computational Fluid Dynamics. A fluid dynamics modeling program (CFX) was used to evaluate the hydrodynamics in a clean square capillary tube. The strain rate profile along the surface of the flow cell is shown in Figure 3, together with the bacterial colonization pattern for comparison. At $1 \mu \mathrm{m}$ above the surface (little variation is seen between the surface and $10 \mu \mathrm{m}$ above the surface), the shear stress increases from a minimum of $2.7 \times 10^{-2} \mathrm{~N} / \mathrm{m}^{2}$ at the corner $(X=0 \mu \mathrm{m})$, to a maximum of $8.4 \times 10^{-2} \mathrm{~N} / \mathrm{m}^{2}$ at the center of the flow path $(X=450 \mu \mathrm{m})$, with an approximate value at $X=200 \mu \mathrm{m}$ of $5.7 \times 10^{-2} \mathrm{~N} / \mathrm{m}^{2}$.

Effluent Analysis. Effluent was captured immediately downstream from the flow cell for direct microscopic and viable cell count analysis. Roughly 10 -fold more E. coli cells were seen in the effluent from the precolonized line than the co-inoculated line $3 \mathrm{~h}$ after inoculation. The E. coli counts from the co-inoculated but not the precolonized line increased with time, and by $96 \mathrm{~h}$ there was no significant difference between the means for the two inoculation cases $(P=0.11)$.

Direct microscopy was performed on the filtered effluent to determine the extent of coaggregation (Figure 4). Initially, the effluent from co-inoculated lines consisted primarily of single, unassociated cells. At later time points, the effluent population consisted mainly of larger $P$. aeruginos $a$ clusters coaggregated with single cells and smaller cell clusters of $E$. coli. In contrast, when $E$. coli cells were introduced into a flow cell precolonized with a mature P. aeruginosa biofilm, $E$. coli cells in the effluent were nearly completely coaggregated at all time points.

\section{Discussion}

Batch culture kinetics reveals an organism's ability to utilize nutrients and reproduce in a given system. In the absence of production of inhibitory compounds, single-species batch kinetics usually predicts which species will out-compete others in a mixed-species batch or chemostat experiment (5-7). However, this is often not the case in biofilm cultures. Many studies have shown slower-growing organisms to coexist with or even out-compete the faster-growing organism in various biofilm systems $(5,7,26)$. In the present study, $E$. coli $\mathrm{O} 157: \mathrm{H} 7$ grew $50 \%$ faster than $P$. aeruginosa $\mathrm{PAO} 1$ in batch cultures. However, when grown together in a flow cell under identical nutrient conditions, P. aeruginosa developed faster, and the final biovolume was approximately 100 times greater than that of $E$. coli. The planktonic growth rate of $E$. coli was the same in the presence or absence of $P$. aeruginosa, suggesting that this effect is not due to the production of inhibitory compounds by $P$. aeruginosa.

Previously, various E. coli O157:H7 strains have been shown to form biofilms $(15,16,27)$ in static batch systems. Additionally, it has been reported that, although the 0157 strain formed a biofilm on stainless steel, the cells were weakly adhered and mild agitation induced sloughing (28). In the present study, E. coli O157:H7 was examined for its ability to form a biofilm alone and in coculture with $P$. aeruginosa in a continuous flow environment. In the present study, $E$. coli was not able to irreversibly attach to the clean glass surface when introduced alone under continuous flow conditions.

Previous research has shown that both biotic and abiotic particles are captured by biofilms. A mature P. aeruginosa biofilm in a glass flow cell was shown to capture a much greater number of Cryptosporidium oocysts than the corresponding abiotic surface (29). Other experiments have revealed similar patterns for the capture of abiotic particles introduced into biofilm-coated surfaces $(30-32)$. When bacteria encounter biofilm-coated surfaces, additional spe- 


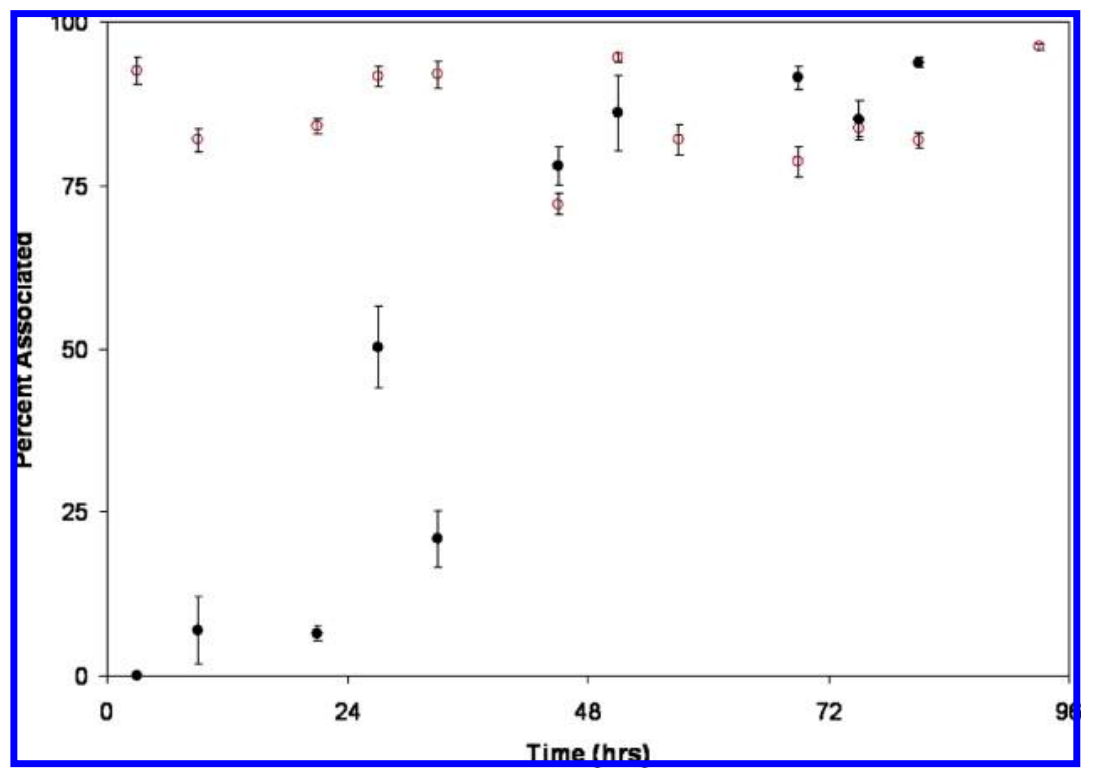

FIGURE 4. Percent (mean) of $E$. coli cells coaggregated with a $\boldsymbol{P}$. aeruginosa cell as determined by direct microscopy of filtered effluent. $E$. coli from the co-inoculated flow cell (closed circles) were initially unassociated but, by 50 h, were predominantly coaggregated. $E$. coli from the precolonized flow cell (open circles) were predominantly coaggregated at all time points. Error bars represent the standard error of the mean for 10 images.

cific coaggregation and coadhesion interactions are known to occur (3).

In the present study, E. coli did adhere in relatively high numbers when introduced continuously into a glass flow cell precolonized with $P$. aeruginosa biofilm. Coaggregated cells in the effluent were observed almost immediately, though surface coadhesion was not seen to a large extent. Attachment occurred primarily underneath the biofilm, rather than on the surface. The $15 \mathrm{~min}$ in which the E. coli cell culture was pumped through the flow cell was not likely to be enough time for cells to move through the intact biofilm, suggesting that advective flow reached the glass-biofilm interface in the mature P. aeruginosa flow-cell grown biofilm through pores or biofilm channels. In fact, closer examination revealed that the biofilm itself was not uniformly attached to the surface but, rather, anchored at a few points with the majority of the biovolume fluctuating with the peristaltic motion of the pump. This movement increases the ability of the biofilm to capture invading E. coli cells from the bulk fluid.

Attempts at colonizing E. coli in the glass capillary were also made by simultaneously inoculating $E$. coli with $P$. aeruginosa. E. coli formed coaggregates with $P$. aeruginosa in the bulk fluid, which then coadhered to the substratum. In all of the observed cases, attached E. coli cells were associated with a $P$. aeruginosa cell. Subsequent biofilm development was monitored using confocal microscopy for a period of $93 \mathrm{~h}$ following the inoculation of $E$. coli and $P$. aeruginosa. Consistently, during early development, Pseudomonas was the dominant species despite E. coli having the higher planktonic growth rate. Development of $E$. colimicrocolonies occurred only along the outer $200 \mu \mathrm{m}$ edge of the flow cell and began only after $P$. aeruginosa migrated away from the edges into the center of the flow path. Bacteria are known to condition surfaces by leaving protein deposits on the glass $(35,36)$, and these surface coatings have been shown to enhance both attachment and biofilm formation (37).

The migration by $P$. aeruginosa was not influenced by the presence of $E$. coli, as the same pattern was seen when grown alone under identical flow and nutrient conditions (data not shown). The mean migration velocity of approximately 7 $\mu \mathrm{m} / \mathrm{h}$ can be compared to other studies where migration velocities of $P$. aeruginosa clusters were influenced by hydrodynamic conditions. In one study (38), biofilm migration velocities were very similar (maximum of $7 \mu \mathrm{m} / \mathrm{h}$ ) and occurred in a direction independent of the fluid flow and in the general direction away from neighboring clusters, suggesting displacement-based velocities. In another study (39), $P$. aeruginosa migrated downstream at a mean velocity of 0.5 $\mu \mathrm{m} / \mathrm{h}$ and $9 \mu \mathrm{m} / \mathrm{h}$ under laminar and turbulent conditions, respectively, suggesting shear-induced velocities.

A major advantage of confocal microscopy is the ability to obtain quantitative information on the reactor as a whole and also at localized regions. This provides insight into where subpopulations exist, allowing for a greater understanding of the various factors involved in mixed-species interactions. For the present study, user script was written in Metamorph to calculate biovolumes at user-defined regions within the flow cell cross-section. A reactor level evaluation of the coinoculated flow cell revealed that $E$. coli comprised less than $1 \%$ of the total biovolume ( $P$. aeruginosa biovolume is greater than $99 \%$ of the total). But when examining the population in the outer $200 \mu \mathrm{m}$ only, E. coli accounted for greater than $50 \%$ of the biovolume.

Both the initial colonization and the more favorable $E$. coli microenvironment occurred at the outer $200 \mu$ m edges of the flow path. Shear force is proportional to the rate of change in velocity along the cross-section and is lowest at the outer edges (corners), increasing to a maximum at the center of the flow path. Previous studies have discussed detachment and bacterial migration phenomena relative to flow cell hydrodynamics (38-41). Additionally, experimental velocity maps from magnetic resonance microscopy in the same capillary flow cell show a zone of approximately 200 $\mu \mathrm{m}$ with a substantially reduced flow velocity gradient (42). The lower-velocity region results in a lower mass transfer rate, though its role in the population heterogeneities observed remains unknown.

Even though 10 -fold more E. coli cells initially adhered in the precolonized versus a co-inoculated flow cell, little to no development of $E$. coli occurred in this system. The biovolume of $E$. coli from co-inoculation increased 100 -fold in $93 \mathrm{~h}$, with no increase in the precolonized system. This highlights the importance of habitat favorability over seeding density in this dual-species biofilm. In one case, the "seeding" of $E$. coli is 10 -fold higher, but the habitat is not as favorable. 
In the case with lower "seeding" but a more favorable habitat, fewer cells initially attach but then increase over the following $93 \mathrm{~h}$. This pattern of growth is very similar to that seen in macro weed ecology models, where habitat favorability dominates over seeding density in determining whether or not the weed will multiply (43). Similarly, while E. coli has the highest seeded population in the precolonized case, it exhibits the most development in the cocolonized case.

\section{Acknowledgments}

This research has been supported by the Keck Foundation and a grant (DAAD 19-03-1-0198) from the Army Research Office. Any opinions, findings, and conclusions or recommendations expressed in this material are those of the authors and do not necessarily reflect the views of the Army Research Office. The confocal microscope was provided via support from the Murdock Charitable Trust. The authors also gratefully thank Dr. Martin Hamilton for his statistical assistance.

\section{Supporting Information Available}

Additional figures are provided. This information is available free of charge via the Internet at http://pubs.acs.org.

\section{Literature Cited}

(1) Stoodley, P.; Sauer, K.; Davies, D.; Costerton, J. Biofilms as complex differentiated communities. Annu. Rev. Microbiol. 2002, 56, 187-209.

(2) Burmolle, M.; Webb, J.; Rao, D.; Hansen, L.; Sorensen, S.; Kjelleberg, S. Enhanced biofilm formation and increased resistance to antimicrobial agents and bacterial invasion are caused by synergistic interactions in multi-species biofilms. Appl. Environ. Microbiol. 2006, 72 (6), 3916-3923.

(3) Rickard, A. H.; Gilbert, P.; High, N. J.; Kolenbrander, P. E.; Handley, P. S. Bacterial coaggregation: an integral process in the development of multi-species biofilms. Trends Microbiol. 2003, 111 (2), 94-100.

(4) Rickard, A. H.; Gilbert, P.; Handley, P. S. Influence of growth environment on coaggregation between freshwater biofilm bacteria. L. Appl. Microbiol. 2004, 96, 1367-1373.

(5) Komlos, J.; Cunningham, A. B.; Camper, A. K.; Sharp, R. R. Interaction of Klebsiella oxytoca and Burkholderia cepacia in dual-species batch cultures and biofilms as a function of growth rate and substrate concentration. Microb. Ecol. 2005, 49 (1), 114-125.

(6) Siebel, M. A.; Characklis, W. G. Observations of binary population biofilms. Biotechnol. Bioeng. 1991, 37 (8), 778-789.

(7) Stewart, P. S.; Camper, A. K.; Handran, S. D.; Huang, C.; Warnecke, M. Spatial distribution and coexistence of Klebsiella pneumoniae and Pseudomonas aeruginosa in biofilms. Microb. Ecol. 1997, 33 (1), 2-10.

(8) Hansen, S.; Rainey, P.; Haagensen, J.; Molin, S. Evolution of species interactions in a biofilm community. Nature 2007, 445 (7127), 533-536.

(9) Filoche, S. K.; Anderson, S. A.; Sissons, C. H. Biofilm growth of Lactobacillus species is promoted by Actinomyces species and Streptococcus mutans. Oral Microbiol. Immunol. 2004, 19 (5), 322-326.

(10) Palmer, R. J.; Kazmerzak, K.; Hansen, M. C.; Kolenbrander, P. E. Mutualism versus independence: strategies of mixed-species oral biofilms in vitro using saliva as the sole nutrient source. Infect. Immun. 2001, 69 (9), 5794-5804.

(11) Castonguay, M. H.; van der Schaaf, S.; Koester, W.; Krooneman, J.; van der Meer, W.; Harmsens, H.; Landini, P. Biofilm formation by Escherichia colis stimulated by synergistic interactions and co-adhesion mechanisms with adherence-proficient bacteria. Res. Microbiol. 2005, 157, 471-478.

(12) Muniesa, M.; Jofre, J.; Garcia-Aljaro, C.; Blanch, A. Occurrence of Escherichia coli O157:H7 and other enterohemorrhagic Escherichia coli in the environment. Environ. Sci. Technol. 2006, 4, 7141-7149.

(13) Dewanti, R.; Wong, A. Influence of culture conditions on biofilm formation by Escherichia coli O157:H7. Int. J. Food Microbiol. 1995, 26, 147-164.

(14) Niemira, B. A. Irradiation sensitivity of planktonic and biofilmassociated Escherichia coli O157:H7 isolates is influenced by culture conditions. Appl. Environ. Microbiol. 2007, 73 (10), 32393244.

(15) Tremoulet, F.; Duche, O.; Namane, A.; Martinie, B.; Labadie, J. C. A proteomic study of Escherichia coli O157:H7 NCTC 12900 cultivated in biofilm or in planktonic growth mode. FEMS Microbiol. Lett. 2002, 215 (1), 7-14.

(16) Uhlich, G. A.; Cooke, P. H.; Solomon, E. B. Analyses of the reddry-rough phenotype of an Escherichia coli O157:H7 strain and its role in biofilm formation and resistance to antibacterial agents. Appl. Environ. Microbiol. 2006, 72 (4), 2564-2572.

(17) Reid, G.; Soboh, F.; Bruce, A. W.; Mittelman, M. Effect of nutrient composition on the in vitro growth of urogenital lactobacilli and uropathogens. Can. J. Microbiol. 1998, 44 (9), 866-871.

(18) Camper, A.; Burr, M.; Ellis, B.; Butterfield, P.; Abernathy, C. Development and structure of drinking water biofilms and techniques for their study. Soc. Appl. Microbiol. Symp. Ser. 1999, $85,1 \mathrm{~S}-12 \mathrm{~S}$.

(19) Camper, A.; Jones, W.; Hayes, J. Effect of growth conditions and substratum composition on the persistence of coliforms in mixed-population biofilms. Appl. Environ. Microbiol. 1996, 62 (11), 4014-4018.

(20) Williams, M.; Braun-Howland, E. Growth of Escherichia coli in model distribution system biofilms exposed to hypochlorous acid or monochloramine. Appl. Environ. Microbiol. 2003, 69 (9), 5463-5471.

(21) Banning, N.; Toze, S.; Mee, B. Persistence of biofilm-associated Escherichia coli and Pseudomonas aeruginosa in groundwater and treated effluent in a laboratory model system. Microbiology 2003, 149, 47-55.

(22) Li, J.; McClellan, S.; Ogawa, S. Accumulation and fate of green fluorescent labeled Escherichia coli in laboratory-scale drinking water biofilters. Water Res. 2006, 40, 3023-3028.

(23) Liu, Y.; Li, J. Role of Pseudomonas aeruginosa biofilm in the initial adhesion, growth and detachment of Escherichia coli in porous media. Environ. Sci. Technol. 2008, 42, 443-449.

(24) Nivens, D.; Ohman, D.; Williams, J.; Franklin, M. Role of alginate and its $\mathrm{O}$ acetylation in formation of Pseudomonas aeruginosa micro-colonies and biofilms. I. Bacteriol. 2001, 183 (3), 10471057.

(25) Herigstad, B.; Hamilton, M.; Heersink, J. How to optimize the drop plate method for enumerating bacteria. L. Microbiol. Methods 2001, 44 (2), 121-129.

(26) Christensen, B. B.; Haagensen, J. A.; Heydorn, A.; Molin, S. Metabolic commensalism and competition in a two-species microbial consortium. Appl. Environ. Microbiol. 2002, 68 (5), 2495-2502.

(27) Sharma, M.; Ryu, J. H.; Beuchat, L. R. Inactivation of Escherichia coli $\mathrm{O} 157: \mathrm{H} 7$ in biofilm on stainless steel by treatment with an alkaline cleaner and a bacteriophage. L. Appl. Microbiol. 2005, 99 (3), 449-459.

(28) Dewanti, R.; Wong, A. Influence of culture conditions on biofilm formation by Escherichia coli O157:H7. Int. J. Food Microbiol. 1995, 26 (1995), 147-164.

(29) Searcy, K. E.; Packman, A. I.; Atwill, E. R.; Harter, T. Capture and retention of Cryptosporidium parvum oocysts by Pseudomonas aeruginosa biofilms. Appl. Environ. Microbiol. 2006, 72 (9), 62426247.

(30) Drury, W.; Stewart, P. S.; Characklis, W. G. Transport of 1-mm latex particles in Pseudomonas aeruginosa biofilms. Biotechnol. Bioeng. 1993, 42, 111-117.

(31) Langmark, J.; Storey, M.; Ashbolt, N.; Stenstrom, T. Accumulation and fate of microorganisms and microspheres in biofilms formed in a pilot-scale water distribution system. Appl. Environ. Microbiol. 2005, 71, 706-712.

(32) Okabe, S.; Kuroda, H.; Watanabe, Y. Significance of biofilm structure on transport of inert particulates into biofilms. Water Sci. Technol. 1998, 38, 136-170.

(33) Medilanski, E.; Wick, L.; Wanner, O.; Harms, H. Mutual influences of Pseudomonas aeruginosa and Desulfovibrio desulfuricans on their adhesion to stainless steel. Biofouling 2003, 19 (2), 125-132.

(34) Bevis, B. J.; Glick, B. S. Rapidly maturing variants of the Discosoma red fluorescent protein (DsRed). Nat. Biotechnol. 2002, 20, 83-87.

(35) Characklis, W.; Marshall, K. Biofilms; John Wiley \& Sons, Inc.: New York, 1990.

(36) Mueller, R. F.; Characklis, W. G.; Jones, W. L.; Sears, J. T. Characterization of initial events in bacterial surface colonization by 2 Pseudomonas species using image analysis. Biotechnol. Bioeng. 1992, 39 (11), 1161-1170.

(37) Hadjiev, D.; Dimitrov, D.; Martinov, M.; Sire, O. Enhancement of the biofilm formation on polymeric supports by sur- 
face conditioning. Enzvme Microb. Technol. 2007, 40 (4), 840848.

(38) Klayman, B.; Klapper, I.; Stewart, P.; Camper, A. Measurements of accumulation and displacement at the single cluster level in Pseudomonas aeruginosa biofilms. Environ. Microbiol. 2008, 10 (9), 2344-2354.

(39) Purevdorj, B.; Costerton, J.; Stoodley, P. Influence of hydrodynamics and cell signaling on the structure and behavior of Pseudomonas aeruginosa biofilms. Appl. Environ. Microbiol. 2002, 68 (9), 4457-4464.

(40) Rupp, C.; Fux, C.; Stoodley, P. Viscoelasticity of Staphylococcus aureus biofilms in response to fluid shear allows resistance to detachment and facilitates rolling migration. Appl. Environ. Microbiol. 2005, 71 (4), 2175-2178.
(41) Stoodley, P.; Lewandowski, Z.; Boyle, J.; Lappin-Scott, H. Structural deformation of bacterial biofilms caused by shortterm fluctuations in fluid shear: an in situ investigation of biofilm rheology. Biotechnol. Bioeng. 1999, 65 (1), 83-92.

(42) Seymour, J.; Codd, S.; Gjersing, E.; Stewart, P. Magnetic resonance microscopy of biofilm structure and impact on transport in a capillary reactor. J. Magn. Reson. 2004, 167, 322327.

(43) Maxwell, B. D. Weed thresholds: The space component and considerations for herbicide resistance. Weed Technol. 1992, 6, 205-212.

ES802218Q 